\title{
TONYUKUK YAZITI'NDA GEÇEN EK TAG ÜZERINE
}

\author{
ERHAN AYDIN ${ }^{*}$
}

\section{Giriş}

Tonyukuk Yazıtı'nın 44. (T II B 9) satırında geçen ve çeşitli şekillerde okunan bir sıfat tamlaması vardır. Bu tamlamanın sıfat kısmı değişik şekillerde okunmuş ve tartışmalara yol açmıştır. Bu kelime genellikle benlig benilig beıülüg șekillerinde okunmakta ve "karlı, karla kaplı"; "benekli"; "ebedi, sonsuz" șekillerinde de anlamlandırılmaktadır. Bu sıfat tamlamasının isim kısmı da ek tag şeklinde okunmakta ve "altın dağ"; "ak dağ” vs. yer adı olarak düşünülmektedir. Bazı araştırıcılar da sözü edilen sıfat tamlamasını tek bir kelime olarak düşünüp benligek veya benligük şekillerinde okumakta ve bir yer adı olarak bildirmektedirler. Esasen üzerinde durmak istediğimiz $E k$ Tag'ın neresi olabileceği konusudur. Yine de yazımızın sonuna doğru beılig kelimesinin arașturıcılar tarafından nasıl okunup anlamlandırıldığına kısaca değineceğiz.

Bilindiği gibi 568-569 yıllarında Batı Kök Türk kağanı İştemi (Çin kaynaklarında Shih-tieh-mi, Bizans kaynaklarında Dilziboul Silziboulos; Arap kaynaklarında da Sincibû $\sim$ Sinj̈̈b̂̂ șeklinde kaydedilen ve yazıtlarda da İstemi $\sim$ Isştemi $\sim$ Eştemi şeklinde okunan adın, Türkçe olmadığını hatta, Bizans kaynaklarında geçen Silziboulos adını da İştemi ile birleştirmenin yanlış olduğunu düşünenler olmuștur (Sinor 2000: 409-410)). Soğd asıllı Maniach başkanlığındaki bir kafileyi Bizans'a elçi olarak yollamıştı. Mani dinine bağlı olduğu adından anlaşılan Maniach (Mani + ach $\sim$ ax Süryanice: "kardeș" (Golden 1992 (2002): 104 not 69)) İskit harfli, büyük bir olasılıkla Soğdca yazılmış bir mektubu Bizans hükümdarına iletunişti. Doğal olarak İstanbul'da Türkçe (Kök Türkçe) bilen tercüman bulmanın zorluğu düşünüldüğünde mektubun, dönemin tüccar kavmi Soğdların diliyle yazılmış olması daha olası görülmektedir. Bizans hükümdarı da Maniach'la birlikte Kilikyalı olduğu bilinen Zemarchos'u Batı Kök Türk

* Yrd. Doç. Dr., Erciyes Üniversitesi, Eğitim Fakültesi, Türkçe Eğitimi Böl./KAYSERI; erhana@erciyes.edu.tr 
kağanına yollamıșt. Zemarchos uzun süren ve oldukça sıkıntılı geçen bir yolculuktan sonra Bat Kök Türk kağanının otağına varmıșt. Daha sonra da elçiler yoluyla karşılıklı ilişkiler devam etmiști. Burada esasen üzerinde durmak istediğimiz Zemarchos'un konuk edildiği kağan otağının neresi olduğunu çeșitli milletlere ait kaynakların yardımıyla ortaya koymaya çalıșmak ve Tonyukuk Yazıtı'nda geçen Ek Tag ile de karşılaşurmaktur.

Yazımızı $E k$ Tag üzerine kurup $E k$ Tag'dan söz eden kaynakları değerlendirmeye çalıșacağız. Bu değerlendirmede Çin, Arap, Bizans ve son olarak da Türkçe kaynakları yani Tonyukuk'un kendisinin kaleme aldığı yazıttaki bilgileri inceleyeceğiz.

I. Cin kaynakları: Batı Kök Türkleriyle ilgili Çin kaynaklarında geçen bilgileri detaylı olarak inceleyen E. Chavannes olmuştur. Chavannes ile birlikte St. Julien ve Çin kaynaklarındaki Türklerle ilgili bilgileri Rusça'ya aktaran Yakineff (Biçurin)'i anmak gereklidir. Ch'u-lo kağandan bahseden Çin kaynakları ekseriyetle kağan otağının İli vadisinde olduğunu kendisine bağlı hanlıklardan birisinin Kuça'nın kuzeyinde diğerinin de Taşkent'in kuzeyinde bulunduğunu söylemektedirler. Yine Ögel'in Chavannes'ten naklettiğine göre Tardu'nun oğlu da Kuça'nın kuzeyinde oturuyormuş (Chavannes 1903: 237'den naklen Ögel 1957: 77 not 70). Çin kaynaklarının en ünlülerinden olan Sui-shu Kuça'nın 170 li (1 li yaklaşık $500 \mathrm{~m}$.) kuzeyinde Pai-shan (beyaz dağ) adlı bir dağ bulunduğunu kaydediyor. Diğer yandan T'ang-shu da Kuça'nın kuzeyinde $A$-chieh-t'ien veya Pai-shan dağının bulunduğunu ve ağzından ateş çıktığını bildiriyor. Bütün bunlardan hareketle Ögel, Ek Tag'n yerini Kuça'nın kuzeyi olarak belirlemektedir (Ögel 1957: 77-78 not 70). Ögel, Bizans kaynaklarında geçen "altındağ" anlamındaki yer adı için de Batı Kök Türk otağının Altay dağlarında olması görüşüne de karşı çıkmakta ve $E k$ Tag'ın Altay dağlarında bulunmasının mümkün olmadığını belirtmektedir (Ögel 1957: 77). Sonuç olarak Ögel, Çin kaynaklarından hareketle $E k$ Tag ile bugünkü Akdağ' 1 birleștirerek yerini Yulduz vadisinin kenarı olarak bildirmektedir (Ögel 1957: 116). Ek Tag'ın Altay Dağları olarak gösterilmesinden yakınan Ligeti de Çin kaynaklarından hareketle $E k$ Tag'a, bugünkü Karaşar'in Kuzey-Batısında bulunan Yulduz vadisinden geçerek yedi günlük bir yolculuktan sonra varıldığını ve bu yerin aşağı yukarı Kuça'nın kuzeyinde olduğunu söyler. Kuça'nın kuzeyinde bat1-kuzey yönünde bir dağ uzandığını ve yerlilerin buraya $A$-cie dağı dediklerini kaydederek $E k T$ ag'ın 
burası olması gerektiğini söylemiştir (Ligeti 1986: 69-70). Taşağıl da Çin kaynaklarından hareketle Ek Tag ile Pai-shan'ı birleștirmiştir. Bu bölge, Tanrı Dağları'nın kuzey silsileleri olarak gösterilmiștir (Taşağıl 2004: 45 not 142).

II. Arap Kaynakları: Arap kaynaklarına göz atmamızın asıl sebebi Batı Kök Türk ve Bizans ilişkisinden ziyade Arap coğrafyacılarının bu bölge ile ilgili verilerinin olup olmadı̆̆ıdır. Arap seyyahı ve tarihçisi Gerdîzî Zeyn el-ahbâr adlı eserinde Kimâklar ülkesini tanıtırken dikkatimizi çeken bir yer adından söz etmektedir. Söylediklerinin ilgi çekiciliği $E k$-Tag'a benzer bir yer adından söz etmesi ile ilgilidir. Aynen alıyorum: "Yol İrtiş nehrini geçince Kimakların çadırına varır. Kimakların sağlam yapıları yoktur. Hepsi ormanlarda, vahşi hayvanlar arasında ve kırlarda otururlar. Hepsi öküz ve koyun sahibidirler. Develeri yoktur. Eğer bir tüccar oraya deve götürürse bir sene yaşamaz. Zira, deve oradaki otları yerse ölür. Kimaklarmn hiç tuzu yoktur. Bir kiși onlara bir batman (rıtl) tuz verirse bir samur derisi alır. Onlann yazlık yiyecekleri at sütüdür. Kış için herkes koyun, at, öküz etinden bol miktarda kurutma yapar. Oraya çok kar yağar. Kırlarda mızrak karın üzerinde durur. Yazın hayvanlarını Ĭğrak vilayeti tarafindaki Öktağ (اوكتاغ ) dedikleri yere götürürler. Kışın kullanmak için yerin altunda ağaçtan yapılımıs su depoları vardır. Yerin altunda bulunan bu sudan içerler. Bu sırada hayvanları kardan su içmeye gidemez. Bunlarm av hayvanları samur ve kakumdur. Reislerine Yabgu denir" (Şeşen 1998: 74). Burada bahsi geçen Öktag'ın İrtiş dolaylarında bir yer olduğu açıktır. Tabii Çin kaynaklarının verdiği bilgilerle örtüşmese de yine de bilinmesinde yarar olduğu düşünülmektedir.

III. Bizans Kaynakları: Aslında Ek Tag sorununun en büyük sebebi Bizans kaynaklandır. İç Asya coğrafyasına gelen Zemarchos ve kafilesi Batı Kök Türk kağanı Dilziboul Silziboulos ile görüșmesinin nerede gerçekleştiği hakkında bazı ipuçları vermektedir. Yazımızın giriş bölümünde de söylediğimiz gibi Batı Kök Türk kağanı, Maniach adlı bir Soğdluyu İskit harfleriyle ve büyük bir olasılıkla da Soğdca yazılmış mektubu vermek ve Sasani'ye karșı ittifak kurmak amacıyla İstanbul'a göndermişti. Bizans hükümdarı da Maniach'la birlikte Kilikyalı Zemarchos'u Batı Kök Türk kağanlığının merkezine göndermişti. Elçi gönderme yoluyla gelişen Kök Türk-Bizans ilişkileri uzun bir zaman daha sürmüștü. Konunun ayrıntısı hakkında Palaz Erdemir 2003'e bakılmalıdır. Batı Kök 
Türk kağanının otağının, Bizans kaynaklarında "Altın Dağ" olarak tercüme

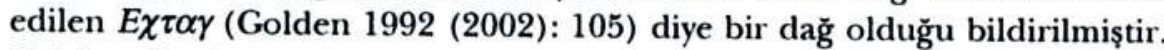
Golden, bu kelimeyi *Ak Tag "Akdağ” olarak düşünmektedir (Golden 1992 (2002): 105); aynca krş. (Chavannes 1903: 235-237); (Moravcsik 1958: 78-79). Menandros'tan naklen verilen bilgide Batı Kök Türk kağanının

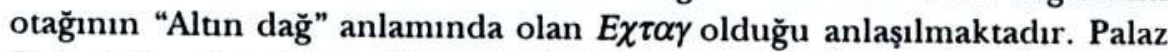
Erdemir'e göre Orhon Yazıtlarında da geçen Ek Tag ile Bizans kaynak-

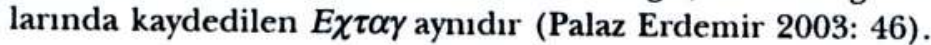

IV. Türk Kaynakları: Son olarak da Türkçe kaynaklardan yani Tonyukuk Yazıtı'ndaki cümlelerden bahsederek $E k$ Tag'ın neresi olduğunu değerlendirmeye çalışacağız. Tonyukuk Yazıtı'nın 44. ve 45. saturları (T II B 9 ve T II G 1) şu şekildedir (metin, Tekin 1994'e göre): T II B 9 biz yämä sülädimiz anı ärtdimiz yençü ügüzüg käçä tinsi ogh aytugma bänlig äk tagıg ärtü T II G 1 tämir kapıgka tägi irtimiz anta yanturtumuz ......; T II B 9 "Biz de sefere çıktık. Onları geçtik. İnci ırmağını geçerek, "tanrı oğlu" denilen (dorukları ak) benekli (yani "karla kaplı") Ek dağını aşarak", T II G 1 "Demir Kapı'ya kadar vardık. Oradan (ordumuzu) geri döndürdük....".

Aslında bu cümlelerde anlaşılmayacak ya da üzerinde tartışılacak tek yer benlig ek tag ibaresidir. Cümle, Tonyukuk, İnel Kagan (İni İl Kagan) ve Tarduş Şad'ın (Bilge Kagan) birlikte katıldıklanı, Altun yış'tan başlayan ve Demir Kapı'ya kadar giden Batı seferidir. Bazı araşturıcılar Bilge Kağan ile Köl Tigin Yazıtlarında da sözü edilen Batı seferi ile Tonyukuk'un bașta bulunduğu batı seferini birbirine karıșturmışlardır. Klyaştornıy, Tonyukuk'un bașta bulunduğu Batı seferinin, Köl Tigin ile Bilge Kagan'ın bau seferinden önce yapıldığını ve bunun da 711 yılının sonu ile 712 yılımın başında olması gerektiğini söylemektedir (Klyaştornıy 1954 (1962): 764 765). Clauson da bu tarihlendirmeyle ilgili olarak bir kuşkudan söz etmektedir. Clauson'a göre belki de Köl ve Bilge'nin Batı seferi ile Tonyukuk'un Bat seferi aynı seferdir (Clauson 1971 (1973-1975): 146). Tonyukuk'un bu seferinin oldukça uzun sürdüğünü Demir Kapı ile Altun $Y \zeta s ̧$ arasındaki uzaklıktan anlamak da mümkündür. Yine Tonyukuk'un cümlelerinde geçen ve Demir Kapı olarak bilinen bölgenin de Semerkant'tan Termez yoluyla Belh'e giden yolun hemen hemen yarısında bulunan Baysun silsilesindeki Buzgala geçidi olduğu söylenmektedir. Yine Demir Kapı'nın Soğdiana ve Tokharistan arasındaki sınır noktalarından biri olduğu da 
kaynaklarda amılmaktadır (Clauson 1971 (1973-1975): 146). Ayrıca Demir Kapı ile ilgili olarak bk. (Thomsen 1896 (2002): 137 not 6). Tonyukuk'un başında bulunduğu ordu, 710-711 veya 711-712 yllarında gerçekleştirilen ve kaynaklarda Bat seferi diye bilinen ünlü seferde sözünü ettiğimiz Demir Kapı'ya kadar ilerlemiștir. Yalnız, Tonyukuk Demir Kapı'ya benlig ek tag' 1 aştıktan sonra ulaşıldığını ifade etmektedir.

V. Kaynakların Değerlendirilmesi: Tonyukuk'un Tensi $\sim$ Tinsi (Çin. t'ien-tsu, bk. (Tekin 1997: 167-168)) ogl Ek Tag olarak belirttiği yer adı hakkında oldukça fazla görüş vardır. Bu görüşlerden bazılarını birincil kaynakları verirken anmıştık. Bu bölümde ise diğer araşturıcıların benlig Ek Tag ile ilgili düșünceleri belirtilecektir. Burada kronolojik sıra izlenmiştir.

Radloff benligäk (?) șeklinde okumuş ve "Bengligäk (?) Gebirge" olarak anlamlandırmıștur (Radloff 1899: 21). Orkun, b"n "iğ $k$ (?) $t^{\prime \prime} g$ 'g okumuş ve "ben ...(?) tuğu" olarak anlamıştur (Orkun 1936: 114). Grousset ise Ek Tag'ın yerini Karaşahr'ın Kuzey-Batısında yukarı Yulduz vadisindeki yazlık merkez olarak düşünmektedir (Grousset 1941 (1980): 96). Malov da bänligäk tag "byangligyak" şeklinde çözümlemiștir (Malov 1951: 64 ve 69). Klyaştornıy ise benlig Ek Tag'dan önceki kelimeyi yatıgma "yatan"; benlig ek tag ibaresini ise Byanglikyak şeklinde okumuş ve Byanglikyak yer adının da büyük bir olasılıkla bir Soğd şatosu olabileceğinden bahisle buranın ünlü Bargar şatosu olma olasılığından söz etmiștir (Klyaștornıy 1954 (1962): 764-765). Aalto ise $b^{i}{ }^{i} l^{i} l^{i} k t^{i} g$ okumuş ve "freudigen (?) GrenzBerg" olarak anlam vermiștir (Aalto 1958: 45). Bununla birlikte Aalto, notlarmda ise neden yatıgma okuduğunu uzun uzun anlattuktan sonra Ek Tag sorunu için de beni benü ile ilişki kurmuştur. Ayrıca Aalto, Kaare Grønbech'in ders notlarında bu yer adımı mäniligak okuduğunu ama kelime listesine ise bäıiligäk alındığına işaret ettikten sonra Grønbech'in bu yer adını haritada büyük Altay Dağları'nda gösterdiğine vurgu yapmıștur (Aalto 1958: 58-59). Giraud da Ongin = Kök Öng ilișkisini ve aymlığını açıklarken $E k$ Tag sorununa da değinmiș ve $E k$ kelimesinin "altın" anlammnda, unutulmuṣ bir söz olduğunu iddia etmiștir. Giraud'un $E k$ kelimesine "altın" anlammı vermesinin tek sebebi Bizans kaynaklarında "altm" anlamında olan yer adının Ek Tag olarak anılmasından kaynaklanmaktadır. Giraud, Tonyukuk Yazıtı'nda geçen $E k$ Tag ibaresine de değinmiş ve Tensi Tinsi oghı aytıgma ibaresindeki kelimeyi yatıgma "yatan" șeklinde 
okuduğu için buramm kutsal bir dağ olduğunu ve burada yatan kişinin Batılı bir Türk olabileceğine işaret ederek bu kişinin Çin'e sadakatten dolayı kendisine saygı gösterildiği şeklinde oldukça hayalî bir açıklama yapmıştur. Tabii bu açıklama da aytıgma "denen, denilen" kelimesinin yatıgma "yatan" olarak okunmasıyla ilgilidir (Giraud 1960 (1999): 73). Yine Giraud Batı Türklerinin karargâhını da Kuça'nın kuzeyinde Tekes vadisi olarak düșünmektedir (Giraud 1960 (1999): 262). Giraud, Tonyukuk Yazıtı'nı işlediği eserinde ise ibareyi benlig $\ddot{A} k$ Tag olarak okumuş ve bänlig "tacheté" olarak düşünmüștür. Giraud bän kelimesi ile de ilgi kurup "tache" olarak açıklamıștur (Giraud 1961: 57 ve 108-109). Stebleva da bänligäk tag okumuş ve "goru bengligek" olarak anlamlandırmıștır (Stebleva 1965: 92 ve 131). Tekin ise benlig ek tag okumuş ve "sacred ÄkTag" olarak çevirmiştir (Tekin 1968: 252 ve 289). Ergin ise benilig Ek tag okumuş ve "mukaddes Ek dağ" olarak anlamlandırmıştur (Ergin 1970: 59 ve 96). Aydarov da beıligek okumuş ve "Bengligek" olarak bir dağ adı olarak düșünmüștür (Aydarov 1971: 332). Aydarov sözlükte ise "nazvanie gorı" olarak anlamlandırmışur (Aydarov 1971: 357). Clauson 1971 yılında yazdığı makalesinde $E k$ Tag'ın Alay silsilesinin (Alay silsilesi Pamir'in Kuzey-Batı kısmı olup, Clauson'un sözü edilen yayımının Türkçe'ye çevirisinde Altay silsilesi yazılmıștır ki bu ad Alay olarak düzeltilmelidir) en batı ucundaki Türkistanskiy silsilesi olması gerektiğine işaret etmiştir (Clauson 1971 (1973-1975): 146). Doerfer, kelimeyi kesinlikle $A k$-tag olarak okuyor ve "weissberg" olarak anlamlandırıyor (TMEN § 1963). Haussig'e göre ise bu dağ Kuça'nın yakınlarında bulunmaktadır (Haussig 1979: 51). RecebovMemmedov da Radloff ve Malov gibi benligäk tag olarak okumuș ve "Benligek Dağı" olarak çevirmişlerdir (Recebov-Memmedov 1993: 120 ve 125). Tekin de bäılig äk tag okumuş ve "(dorukları ak) beneḳli (yani "karla kaplı") Ek dağı" olarak anlamlandırmıştır (Tekin 1994: 18-19). Tekin, notlarında ise $E k$ Tag'n Tien Shan ya da Tanrı Dağları olduğunu düşünmektedir (Tekin 1994: 47). Gömeç, Ek Tag'ı Tekes Nehri yakınındaki Karașahr'ın Kuzey-Batısında bir yere koyar. Yalnız cümlelerden anlaşıldığı kadarıyla Bizanslıların belirttiği $E k$ Tag ile Tonyukuk'un sözünü ettiği $E k$ Tag aynı yer adı olarak görülmüş olmalıdır ki Tonyukuk Yazıtı'nın II. Taşın Batı yüzü ile ilgili açıklamalarda Ek Tag'a değinilmiştir (Gömeç 1997: 16 not 55). Rybatzki, bu yer adının aynı adı taşıyan diğer adlarla karışturılmamasına işaret ettikten sonra Tonyukuk'un Tensi $\sim$ Tinsi oglı diye andığı Ek Tag'ın yeri konusunda Clauson'a katıldığını bildirmek- 
tedir (Rybatzki 1997: 115-116 not 308). Karcavbay da ibareyi benlik Ek tag okumuş ve "Benlik Ek Tau" olarak çevirmiștir (Karcavbay 2003: 219 ve 224). Son olarak da Berta, ibareyi bäılig äk tag okumuṣ ve "Benglig Ek hegyet" olarak anlamlandırmıştr (Berta 2004: 67 ve 85).

Görüldüğü gibi $E k$ Tag, hem okuma ve anlamlandırma hem de bulunduğu coğrafi yer bakımından hâlledilmemiş bir sorun olarak karşımızda durmaktadır. Fakat bäılig benilig Ek Tag şeklindeki okuyuşun yaygmlık kazandığı anlaşılmaktadır. Bizans kaynaklarında geçen ve "altun" anlamında bir dağ olduğu ifade edilen $E k$ Tag ile Tonyukuk Yazıtı'nda sözü edilen ve Yençü Ügüz'ü (Sirderya) geçip ulașılan benlig ek tag'ın aynı yer olmadığı kuşkusuzdur. Aslında bütün sorun da buradadır. Menandros'tan nakledilen Ek Tag ile Tonyukuk'un bahsettiği benlig Ek Tag'ın aymı olması coğrafi olarak da mümkün değildir.

VI. Sonuç ve Öneriler: Menandros'tan nakledilen $E k$ Tag'ın Batı Kök Türk kağanının otağı olduğunda kușku yoktur. Bu Ek Tag büyük bir olasılıkla, Çin kaynaklarında sözü edilen ve Kuça'nın kuzeyinde Tekes nehri ile Ebi-Nor gölü arasında bir yer olmalıdır. Tonyukuk'un sözünü ettiği benlig Ek Tag da Clauson'un dediği gibi Pamir'in Kuzey-Batı silsilesini olușturan Alay dağlarının Batı bölümünde olmalıdır. Hatta Radloff Aus Sibirien adlı eserinin Zerefșan Vadisi'nden söz ettiği bölümde Ek Tag diye bir dağdan söz eder. Bu dağın Zerefșan Vadisi'nde bulunduğundan bahisle dağın çok yüksek olmadığını ancak dik olduğu için turmanmanın çok zor olduğunu söyler (Radloff 1957: 439-440). Eğer tespitlerimiz doğruysa bu dağın așılmasından sonra Demir Kapı'ya yani Baysun bölgesinde bulunduğu söylenen (Clauson 1971 (1973-1975): 146) doğal dağ geçidine varılmış olur. Bu söylediklerimiz coğrafi olarak herhangi bir engelle karşılaşmamaktadır. Aslında Ak Tag Ak Tau $\sim E k$ Tag $\sim E k$ Tau şeklinde Asya'da bir çok dağ veya yer adı vardır. Ancak bizim aradığımız $E k$ veya $A k$ Tag'a Yençü Ügüz'ün aşılmasından sonra varılmıștır. Bugünkü Dușanbe'nin kuzeyi ile Semerkand'ın Batısına düșen bir noktada (bk. harita) $A k-T a k$ adlı bir yeri de araşturıcılarm dikkatlerine sunmak istiyoruz. 
Böylelikle Bizans kaynaklarında "altn" anlamı verilen Ek Tag'ı Tonyukuk Yazıtı'nda geçen $E k$ Tag ile ayn olmadığı ortaya çıkmakta ve "altun" anlaumnda eskiden kullanıldığ farzedilen bir ek kelimesi aramaya da gerek kalmamaktadır. Üstelik altun kelimesi Altay dillerinde sıkça kullanılan bir kelimedir. Altay<*altan ?, Tü. altun > Mo. altan krş. Altayca n $>n / y$ (Golden (1992) 2002: 96). Tabii ki Bizans kaynaklarınm sözünü ettiği $E k$ Tag, Altay (Altum Y/ş) dağlarının uzantısında bulunduğu için Bizans kaynaklarında bu anlanda kullanıldığım zannediyoruz. Ek Tag'dan önce geçen ve yazımızın bașında değindiğimiz sıfat tamlamasının sıfat kısmum olușturan benlig kelimesini de benilig benülïg "ebedi, sonsuz" șeklinde düşünmekten çok "doruklu, doruklu dağlar" olarak düșündüğümüzü ve Moğolcada "doruklu dağlar" anlammda kullanılan möndüg kelimesi ile ilișkilendirmek istediğimizi belirtmek istiyorum (Lessing 2003: 855). 


\section{KAYNAKLAR}

AALTO, P.; G. J. RAMSTEDT; J. G. GRANÖ 1958, "Materialien zu den alttürkischen Inschriften der Mongolei", JSFOu, LX/7, 3-91.

AYDAROV, G. 1971, Yazık Orhonskix Pamyatnikov Drevnetyurkskoy Pis'mennosti VIII veka, Alma-ata: Akademiya Nauk Kazakskoy SSR.

BERTA, Á. 2004, Szavaimat Jól Halljátok, A Türk és Ujgur Rovásírásos Emlékek Kritikai Kiadása, Szeged: Jate Press.

CHAVANNES, E. 1903, Documents sur les T'ou-kiue (Turcs) Occidentaux, St-Petersburg.

CLAUSON, S. G. 1971, "Some notes on the inscription of Tonukuk", Studia Turcica, 1971, 125-132. Türkçeye çevirisi: "Tonyukuk Abidesi Hakkında Bazı Notlar”, çev. İnci Enginün, TM, 18, 1973-1975, 141148.

DOERFER, G. 1975, Türkische und Mongolische Elemente im Neupersischen, Band IV: Türkische Elemente im Neupersischen (Schluss) und Register zur Gesamtarbeit, Wiesbaden: Franz Steiner Verlag.

ERGIN, M. 1970, Orhun Abideleri, İstanbul.

GIRAUD, R. 1960, L'empire des Turcs Célestes, Les règnes d'Elterich Qapghan et Bilge (680-734), Paris. Türkçeye çevirisi: Gök Türk İmparatorluğu, İlteriş, Kapgan ve Bilge'nin Hükümdarlıkları (680734), çev. İsmail Mangaltepe, İstanbul, 1999. Ötüken Yaymları.

,1961, L'Inscription de Bam Tsokto, Paris: Librairie d'Amerique et d'Orient.

GOLDEN, P. B. 1992, An Introduction to the History of the Turkic Peoples, Wiesbaden: Otto Harrassowitz. Türkçeye çevirisi: Türk Halkları Tarihine Giriş, çev. Osman Karatay, Ankara, 2002. KaraM Yaymları.

GÖMEÇ, S. 1997, Kök Türk Tarihi, Ankara: Türksoy Yayınları.

GROUSSET, R. 1941, L'empire des Steppes (Attila, Gengis-Khan, Tamerlan), Paris. Türkçeye çevirisi: Bozkır Imparatorluğu, Attila/Cengiz Han/Timur, çev. M. Reșat Uzmen, İstanbul, 1980. Ötüken Yaymları. 
HAUSSIG, H. W. 1979, "Byzantinische Quellen über Mittelasien in ihrer historischen Aussage", Prolegomena to the sources on the history of pre-islamic Central Asia. Ed.: J. Harmatta. Budapest, 41-60.

KARCAVBAY, S. 2003, Orxon Muralar1, Astana.

KLYAŞTORNIY, S. G. 1954, "İz istorii bor'b1 narodov Sredney Azii protiv arabov (po tekstı rukopisi)", Épigrafika Vostoka, 9, 1954, 55-64. Türkçeye çevirisi: "Orta Asya Milletlerinin Araplar'a Karșı Mücadelelerine Dair (Orhun Yazıtlarına Göre)”, çev. İsmail Kaynak, Belleten, XXVI/104, 1962, 763-776.

LESSING, F. D. 2003, Moğolca-Türkçe Sözlük, çev. Günay Karaağaç, Ankara: Türk Dil Kurumu Yayınları.

LIGETI, L. 1986, Bilinmeyen $\dot{I}_{\zeta}$ Asya, çev. Sadrettin Karatay, Ankara: Türk Dil Kurumu Yayınları.

MALOV, S. E. 1951, Pamjatniki drevnetyurkskoj pis'mennosti, tekstı i issledovaniya, Moskva-Leningrad.

MORAVCSIK, Gy. 1958, Byzantinoturcica I-II, 2. bs., Berlin.

ORKUN, H. N. 1936, Eski Türk Yazıtları I, İstanbul: Türk Dil Kurumu Yayınları.

ÖGEL, B. 1957, "Doğu Göktürkleri Hakkında Notlar Vesikalar”, Belleten, XXI/81, 1957, 81-137.

PALAZ ERDEMIR, H. 2003, VI. Yüzyl Bizans Kaynaklarnna Göre GöktürkBizans İlişkileri, İstanbul: Arkeoloji ve Sanat Yayınları.

RADLOFF, W. 1899, Die alttürkischen Inschriften der Mongolei, Zweite Folge, St-Petersburg.

__ 1957, Sibirya'dan, çev. Ahmet Temir, İstanbul: Maarif Vekâleti Yayınları.

RECEBOV, E.; Y. MEMMEDOV 1993, Orhon-Yenisey Abideleri, Bakı.

RYBATZKI, V. 1997, Die Toñukuk-Inschrift, Szeged: Studia Uralo-Altaica: 40.

SINOR, D. 2000, “(Kök) Türk İmparatorluğu'nun Kuruluşu ve Yikılıșı”, çev. Talat Tekin, Erken İ Asya Tarihi, İstanbul, 2000, 383-424. İletișim Yaymları.

STEBLEVA, I. V. 1965, Poeziya Tyurkov VI-VIII. vekov, Moskva. 
ȘEŞEN, R. 1998, İslam Coğrafyacılarma Göre Türkler ve Türk Ülkeleri, 2. bs., Ankara: Türk Kültürünü Araștırma Enstitüsü Yayınları.

TAȘAĞIL, A. 2004, Çin Kaynaklarma Göre Eski Türk Boyları, Ankara: Türk Tarih Kurumu Yayınları.

TEKiN, T. 1968, A Grammar of Orkhon Turkic, Bloomington, The Hague: Indiana University Publications, Uralic and Altaic Series: 69. , 1994, Tunyukuk Yazıtı, İstanbul: Simurg Yayınları. , 1997, "Notes on some Chinese Loanwords in Old Turkic", Türk Dilleri Araştırmalanı, 7, 1997, 165-173.

THOMSEN, V. 1896, "Inscriptions de l'Orkhon déchiffrées", MSFOu, 5, 1896, 1-224. Türkçeye çevirisi: Orhon ve Yenisey Yazıtlarınm Cözümü İlk Bildiri, Cözülmüş Oıhon Yazıtları, çev. Vedat Köken, Ankara, 1993. Genişletilmiș ikinci baskı, Ankara, 2002: Türk Dil Kurumu Yayınları.

TMEN: bk. G. DOERFER 

Erhan Aydin

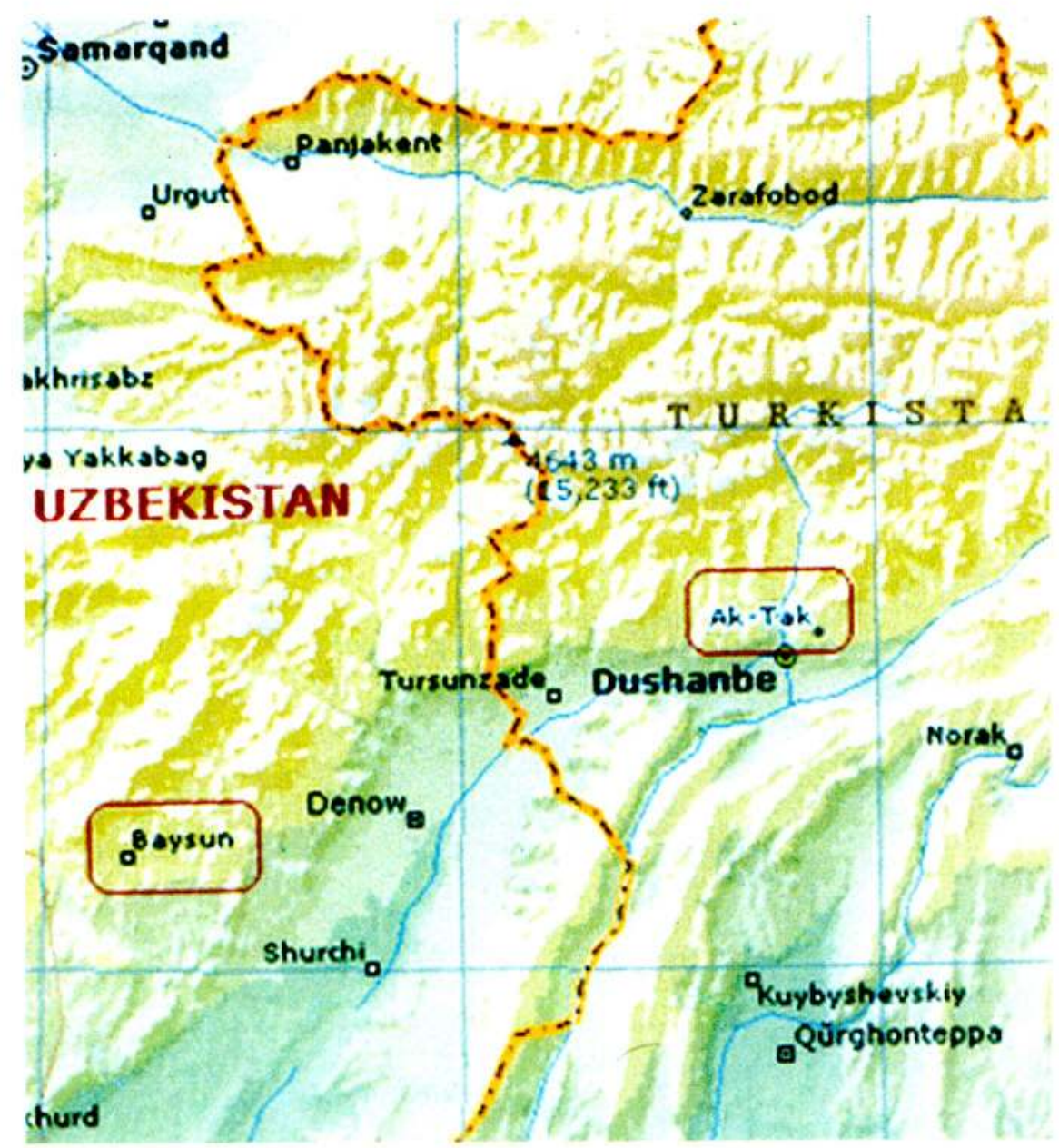

Harita 1 
